\title{
Modeling of Communication Strategies for Reducing Public Road Accidents Involving Two-Wheel Motorized Vehicles in Urban Areas: Case of Cotonou and Parakou Cities in Benin
}

\author{
François Agossou ${ }^{1}$, *, Jacques Saizonou ${ }^{1}$, Castro Hounmenou ${ }^{2}$, Blasselle Houssou ${ }^{1}$, \\ Assumption Hounsa ${ }^{1}$, Gyslain Mahoutin Zannou ${ }^{3}$, Cyriaque Ahodekon ${ }^{4}$, Patrick Makoutode ${ }^{1}$, \\ Virginie Mongbo ${ }^{1}$, Edgard-Marius Ouendo ${ }^{1}$ \\ ${ }^{1}$ Regional Institute of Public Health, University of Abomey-Calavi, Ouidah, Benin \\ ${ }^{2}$ Institute of Mathematics and Physical Sciences, University of Abomey-Calavi, Porto-Novo, Benin \\ ${ }^{3}$ Faculty of Economics and Administration, University of Abomey-Calavi, Abomey-Calavi, Benin \\ ${ }^{4}$ Pluridisciplinary Doctoral School 'Spaces, Cultures and Development', University of Abomey-Calavi, Abomey-Calavi, Benin
}

Email address:

francogoss@yahoo.fr (F. Agossou), agossouf@who.int (F. Agossou)

${ }^{*}$ Corresponding author

\section{To cite this article:}

François Agossou, Jacques Saizonou, Castro Hounmenou, Blasselle Houssou, Assumption Hounsa, Gyslain Mahoutin Zannou, Cyriaque Ahodekon, Patrick Makoutode, Virginie Mongbo, Edgard-Marius Ouendo. Modeling of Communication Strategies for Reducing Public Road Accidents Involving Two-Wheel Motorized Vehicles in Urban Areas: Case of Cotonou and Parakou Cities in Benin. Central African Journal of Public Health. Vol. 7, No. 1, 2021, pp. 23-31. doi: 10.11648/j.cajph.20210701.13

Received: November 25, 2020; Accepted: December 10, 2020; Published: January 22, 2021

\begin{abstract}
Introduction: Road accidents are one of the leading causes of morbidity and mortality in the world. To reduce their scale, some approaches have been favored, such as communication actions. This work aimed to propose an integrated model for the effective reduction of road accidents among motorized two-wheeled vehicle drivers (2WD) in urban areas in Benin. Method: This is a cross-sectional and analytical study of road users $(\mathrm{n}=1497)$ in Cotonou and Parakou. The data was collected on a mobile phone using CSPro software and analyzed in three stages: descriptive analysis, multivariate analysis for the selection of variables significantly affecting the variable to be explained, and the development of the integrated model using the Multilayer Perceptron Neural Network. Results: The study showed that communication actions, advocacy, contextual interventions, belief, certain individual characteristics of users, were significantly associated with the reduction of road accidents. The communication model that emerges from this is akin to "persuasive engaging" communication. Conclusion: This study demonstrated the importance of using an integrated national communication program to strengthen road safety. To do so, they need to promote respect for the Highway Code by emphasizing the sanctity of human life must be combined with relevant accompanying measures.
\end{abstract}

Keywords: Public Road Accidents, Motorized Two-Wheelers, Road Code, Modeling, Benin

\section{Introduction}

With 1.35 million deaths each year, worldwide (18.2 deaths per 100,000 inhabitants), Public Road Accidents (PRA) are the eighth leading cause of death for all age groups and the first among young people aged 5 to 29 [1]. The global road fatality rate of 18.2 deaths per 100,000 inhabitants varies by region. The regions of Africa and Southeast Asia (26.6 and 20.7 deaths per 100,000 inhabitants, respectively) have the highest regional rates of death from PRA while the regions of America and Europe have the lowest rates (15.6 and 9.3 deaths per 100,000 inhabitants respectively) [1]. Like other African countries, Benin is increasingly confronted with PRA with relatively significant involvement of motorized two-wheeled vehicle drivers (2WD). Indeed, according to statistics provided by the National Road Safety Center (CNSR), Benin in 2015 recorded 5,992 PRA, a likely increase of $9.4 \%$ compared to the situation in 2013 [2]. 
To reduce the incidence of PRA among road users in general and motorcyclists in particular, governments and international organizations in partnership with WHO, have stepped up their response to the road safety crisis through the Decade of Action for Road Safety (2011-2020) and the 2030 Agenda for Sustainable Development [3, 4]. Consequently, certain approaches have been favored to fight effectively against the problem of PRA. Among these, communication actions are considered to be an important axis of prevention both in Africa and globally. In Benin, road safety communication actions are varied: awareness-raising, media campaigns, interpersonal communication, education on road safety, etc. But real issues arise when designing and implementing these interventions. We can note the existence of a methodological deficiency that is to say that few campaigns are based on a theoretical framework; there is also a significant lack of rigorous (post-campaign) evaluations. We also note the anarchic and massive use of the threat in the vast majority of the countryside. However, the productive use of the threat, especially the emotional dosage, is a very delicate business, because the recipients can easily reject the message. Insufficiencies are also observed regarding the unavailability of resources limiting the implementation of large-scale communication actions. Besides, several studies report that communication actions, on their own, are insufficient to sustainably and significantly reduce PRA [5].

Facing the limits of previous road safety communication actions illustrated by the continuous increase in PRA and deaths involving the survey motorcycles [2], one of the effective solutions we are considering relates to the restructuring of interventions promotion of road safety. This restructuring will be carried out in particular through the construction of a better structured and integrated model that will take into account several aspects while changing the implementing techniques. The model sought is largely inspired by psycho-social behavioral models. This work aimed to study an integrated model of PRA reduction among 2WD in Benin in general and particularly in the communes of Cotonou and Parakou.

\section{Methods}

\subsection{Study Framework}

This study was carried out in Benin and particularly in the communes of Cotonou and Parakou. Benin is a country in the West African sub-region that covers an area of $114,763 \mathrm{~km}^{2}$. The projections of the National Institute of Statistics and Economic Analysis (INSAE) give a population of 11,154,174 inhabitants in 2018 [6]. Nationally, the entire road network was estimated at 2,684.82 kilometers of paved roads and $3,259.77$ kilometers of unpaved roads in 2016 [7]. Administratively, Benin has 12 departments divided into 77 municipalities including Cotonou and Parakou [6]. The city of Cotonou is the economic capital of the country which has the highest number of drivers of two-wheeled vehicles compared to other cities in Benin. Its surface area is $79 \mathrm{~km}^{2}$ and its population was estimated at 2,401,067 million inhabitants in 2018 [6]. The road network is developed there with many paved roads. The city has three main means by which taxi-motorcycles are more used by the inhabitants. The city of Parakou is situated at $407 \mathrm{~km}$ from Cotonou and is the main city in northern Benin. It covers an area of $441 \mathrm{~km}^{2}$ and had 255,478 inhabitants [6].

\subsection{Type and Period of Study}

This was an analytical cross-sectional study that was carried out in August 2020 in the communes of Cotonou and Parakou.

\subsection{Study Population}

The study population consisted of road users. These were pedestrians, users of two-, three- and four-wheeled vehicles.

Inclusion criteria

The sampling populations involved in this study are pedestrians who travel by motorcycle taxi, users of two, three, and four-wheeled vehicles residing in one of the two communes (Cotonou and Parakou) at least within the last three years before the investigation.

Exclusion criteria

Pedestrians rarely traveling in motorcycle taxis, users under the age of 18, users residing in one of the two communes less than three years before, users refusing to participate in the survey were excluded from the study.

\subsection{Sampling Method}

Random 2-degree cluster sampling is performed to select road users. The 1 st stage relates to the city districts of the communes of Cotonou and Parakou then the 2nd stage relates to households (users per house and household). A total of sixty (60) first-degree clusters (city districts) were selected by systematic random choice based on the complete list of city districts in each of the municipalities by applying a survey step. This survey step is determined by making the ratio between the total of households [8] and the total number of clusters considered. Proportional distribution of the number of clusters per municipality is made based on the total number of households per municipality. The 1 st cluster is identified by drawing lots for a number smaller than the survey. From this selected cluster, the other clusters are drawn by adding each time the survey step. Then, for the selection of targets: from an intersection located in the center of each city district (degree 1 cluster selected), the investigator chooses a random direction. And then he spins a pen and throws it in the air; the direction is indicated by the tip of the pen. Following this direction, it proceeds to the selection of households (cluster of degree 2). The first house is the first one to be visited. Then the investigator proceeds step by step until he reaches the number of road users to be investigated in each cluster.

The minimum number of road users to be investigated calculated by Schwartz formula was:

$$
n=\frac{z_{\alpha}^{2} \times p(1-p) \times e}{i^{2}} \text {, avec }
$$


p: prevalence of $50 \%$ due to the lack of an estimate of the proportion of road users thinking a significant reduction in PRA is possible

$z_{\alpha}$ : value of the reduced gap for an alpha risk of $5 \%$ $\left(z_{\alpha}=1.96\right)$;

i: precision desired for the results $(4 \%)$;

e: cluster effect (2)

We got $n=\frac{1,96^{2} \times 0,5(1-0,5) \times 4}{0,04^{2}}=1200$

The minimum size of the population surveyed in our study being 1200 . We questioned a total of 1500 road users in the two cities. After purification of the database, the total number of representative samples to which the survey relates comes down to 1497.

\subsection{Data Collection Techniques and Tools}

A questionnaire survey was carried out. The data was collected after a pre-survey carried out in the Abomey-Calavi health zone before submitting the questionnaire to road users in the cities of Cotonou and Parakou. It made it possible to readjust the questionnaire so as to make it applicable in the study sites.

\subsection{Data Processing and Analysis}

\subsubsection{Data Analysis}

The data collected digitally on a laptop was analyzed in several stages. First, the analysis made it possible to describe the general characteristics of the sampling populations and then to proceed with the actual modeling of the communication strategy.

\subsubsection{Descriptive Analysis}

It enabled to describe: the general characteristics of the sampling populations (socio-demographic characteristics and extent of the phenomenon of PRA among 2WD) in terms of the political and strategic context (assessment of the strategies to be adopted in terms of road safety); psychosocial diagnosis (behavior to be promoted and motivating to act, attitudes, beliefs, obstacles related to the targeted behavior); psychosocial interventions (actions at the attitudinal level to reduce PRA, actions towards beliefs, actions against obstacles and difficulties to strict compliance with the highway code) and finally their; perception on the relevance of a combined approach by means of calculating absolute frequencies and percentages, for the qualitative variables and of the average and standard error for the quantitative variable.

\subsubsection{Modelization}

For the identification of the determinants of a significant reduction of PRA, proceeding the use of variable selection models such as classical step-by-step logistic regression (Stepwise selection) and regularized logistic regression (LASSO method, RIDGE and ELASTICNET) [9] on the binary explained variable, that is equal to 1 when the surveyed estimates a significant reduction in PRA among 2WD and if not 0 . The explanatory variables are in total 139 and are composed of psychosocial, organizational, individual, contextual, and related to the proposed actions. The total number of sampling populations retained after purification of the database was 1497. Before the implementation of these variable selection models, the data set was partitioned into training data $(70 \%)$ and test data $(30 \%)$. The learning data was used to build the models and the test data to assess their generalization abilities.

Seven performance criteria are used for the selection of the best model that best fits the data and capable of facilitating the interpretation of the information and which are: sensitivity (true positive rate, TPR), the true negative rate (TNR), precision, the F-score (F-measure), the correct classification rate (accuracy), the area under the ROC curve (area under the Receiver Operating Characteristic, ROC) and the concordance on test data. The closer the values of these criteria are to or equal to 1 , the better the model from the best model selected, the variables retained were assigned to their corresponding categories, namely: the category of psychosocial, organizational, individual, contextual and related to the proposed actions.

Then, the statistical model of integrated communication for explanatory and predictive purposes for the reduction of PRA among 2WD was established in Multilayer Perceptron Neural Networks (Multilayer Perceptron Neural Network (MPNN), an alternative to the non-compliance with the conditions of application of the classical logistic regression. They can take into account the complexity of the relationship between variables and possible noises. They have demonstrated their efficiency in predicting empirical data compared to the classical method and are applied in various fields [9-13]. Its schematic drawing is described below $[14,15]$.

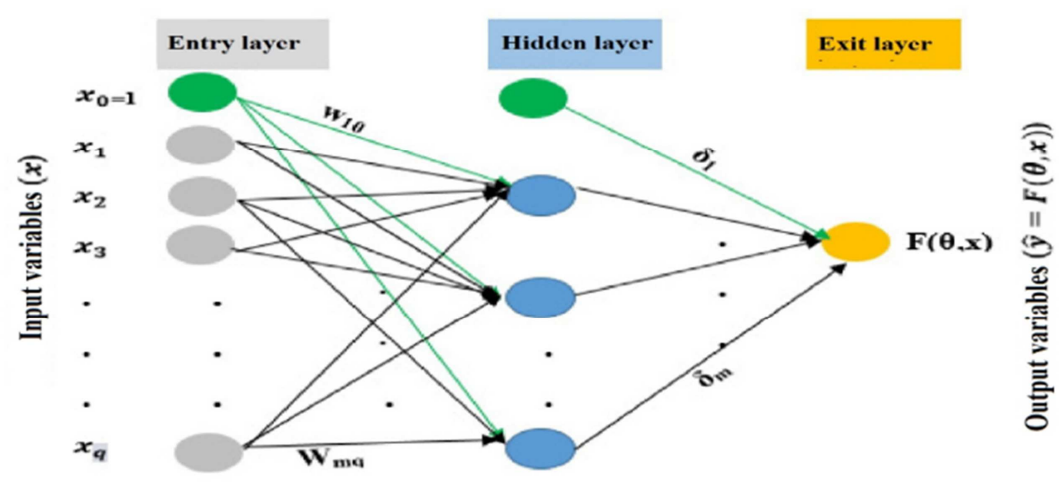

Figure 1. Schematic drawing of the MPNN model used. 
For implementing the MPNN model, the same conditions as previously described in the context of the selection of variables have been respected. Here the explanatory variables are those retained from the best variable selection model. The same performance criteria are used to select the best MPNN designing for good prediction by varying the number of neurons in the hidden layer. Software R 3.3.6: is used for data processing and analysis [16].

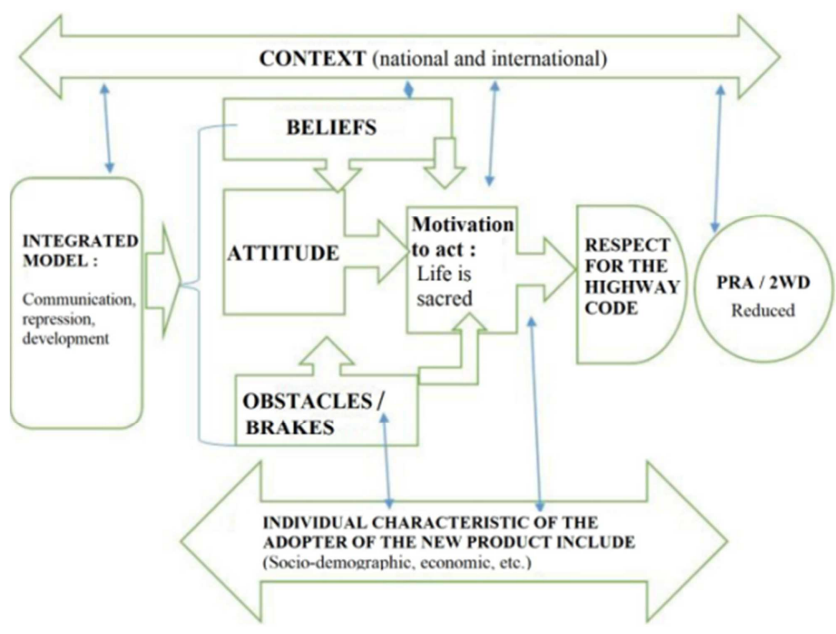

Figure 2. Integrated communication model proposed.

\section{Results}

\subsection{Socio-demographic Characteristics of the Representative Sample Studied}

A total of 1,497 representative samples were included in the study, of which $73.75 \%$ resided in Cotonou against $36.25 \%$ in Parakou. Men were more represented $(87.31 \%)$, with a sex ratio of 6.88 . Young people $(49.37 \%)$ were equally represented The majority of sampling populations were from Christian religion (72.61\%), Fons ethnicity $(58.12 \%)$, and unmarried marital status (39.75\%) and had a low monthly income (79.76\%). Regarding professional status, one in ten were selfemployed (41.48\%) and nearly three in ten $(27.19 \%)$ were motorcycle taxi drivers. The subjects surveyed were mainly users of motorized two-wheeled vehicles (74.01\%). Table 1 presents the socio-demographic characteristics of road users in the cities of Cotonou and Parakou.

Table 1. Distribution of socio-demographic characteristics of road users in the cities of Cotonou and Parakou in 2020.

\begin{tabular}{lll}
\hline Socio-demographic characteristics & Numbers & Percentages (\%) \\
\hline Age ranges & & \\
Youths & 739 & 49,37 \\
Adults & 748 & 49,97 \\
Old & 10 & 0,67 \\
Sex & & \\
Male & 1307 & 87,31 \\
Femal & 190 & 12,69 \\
Nationality & & \\
Beninese & 1480 & 98,86 \\
Other & 17 & 1,14 \\
\hline
\end{tabular}

Table 1. Continued.

\begin{tabular}{|c|c|c|}
\hline Socio-demographic characteristics & Numbers & Percentages (\%) \\
\hline \multicolumn{3}{|l|}{ Educational level } \\
\hline None/Literate & 83 & 5,54 \\
\hline Primary & 263 & 17,57 \\
\hline First cycle of secondary school & 306 & 20,44 \\
\hline Second cycle of secondary school & 360 & 24,05 \\
\hline Higher & 485 & 32,40 \\
\hline \multicolumn{3}{|l|}{ Ethnic } \\
\hline Fon & 870 & 58,12 \\
\hline Bariba & 215 & 14,36 \\
\hline Mina & 148 & 9,89 \\
\hline Yoruba & 104 & 6,95 \\
\hline Adja & 101 & 6,75 \\
\hline Lokpa & 22 & 1,47 \\
\hline Bétamaribé & 18 & 1,20 \\
\hline Peulh & 10 & 0,67 \\
\hline Others & 9 & 0,60 \\
\hline \multicolumn{3}{|l|}{ Marital status } \\
\hline Single & 595 & 39,75 \\
\hline Married & 467 & 31,20 \\
\hline Cohabitation & 414 & 27,66 \\
\hline Divorced & 11 & 0,73 \\
\hline Widower & 100 & 0,67 \\
\hline \multicolumn{3}{|l|}{ Professional status } \\
\hline Freelance & 621 & 41,48 \\
\hline Taxi-moto driver & 407 & 27,19 \\
\hline Contractual employee & 143 & 9,55 \\
\hline Permanent employee & 93 & 6,21 \\
\hline Home support & 74 & 4,94 \\
\hline Unemployed & 57 & 3,81 \\
\hline Manual worker & 49 & 3,27 \\
\hline Apprentice & 36 & 2,4 \\
\hline Employer & 16 & 1,07 \\
\hline A cooperative member & 1 & 0,07 \\
\hline \multicolumn{3}{|l|}{ Monthly income } \\
\hline Low & 1194 & 79,76 \\
\hline Average & 242 & 16,17 \\
\hline High & 61 & 4,07 \\
\hline \multicolumn{3}{|l|}{ Type of users } \\
\hline Pedestrian & 261 & 17,43 \\
\hline 2 Motorized wheels & 1108 & 74,01 \\
\hline 3 Motorized wheels & 26 & 1,74 \\
\hline 4 Motorized wheels & 102 & 6,81 \\
\hline
\end{tabular}

\subsection{Extent of the PRA among 2 WD According Representative Samples}

The phenomenon of road accidents involving $2 \mathrm{WD}$ is unanimously recognized by $93.8 \%$ of users against $5.5 \%$ who did not recognize it and 0.62 did not notice.

\subsection{Political and Strategic Context2WD}

Among the strategies to be adopted for strengthening road safety, implementing road safety policy $(90.78 \%)$ and enhancement of the role played by NGOs working in road safety $(52.77 \%)$ were the interventions most likely to contribute to reducing PRA according to representative samples.

\subsection{Psycho-social Diagnosis}

\subsubsection{Behavior to Promote and Motivating to Act}

To bend the upward curve of the PRA among 2WD, it 
emerges from this table that the type of fatalistic attitude $(98.73 \%)$ and that of the "pro-doping" type in motorcycle driving $(95.86 \%)$ are the best emerged. Beliefs regarding the non-severity of PRA involving motorcycles $(97.66 \%)$ followed by those regarding the effectiveness of driving control (85.30\%). Beliefs about supernatural protection (83.83\%) were also seen as limiting compliance with the Highway Code. Table 4 presents the assessment of attitudinal values with a view to strict compliance with the Highway Code.

Table 2. Distribution of users of $2 W D$ according to the assessment of attitudinal values with a view to strict compliance with the Highway Code as well as their belief in Cotonou and Parakou in $2020(N=1497)$.

\begin{tabular}{llll}
\hline & \multicolumn{3}{c}{ Appreciation (\%) } \\
\cline { 2 - 4 } & Good & Bad & Neither \\
\hline Attitudes & 1,07 & 98,73 & 0,20 \\
Fatalistic attitude & 3,07 & 95,86 & 1,07 \\
Motorcycle pro doping driving attitude & 15,50 & 62,06 & 22,44 \\
Discernment attitude & & & \\
Belief & 0,94 & 97,66 & 1,40 \\
Non-seriousness of PRA involving motorcycles & 3,14 & 83,83 & 13,03 \\
Supernatural protection & 1,74 & 85,30 & 12,96 \\
Driving control efficiency & & & \\
\hline
\end{tabular}

\subsubsection{Obstacles and Brakes Related to the Targeted Behavior: Items Assessed}

According to the representative samples, the relevant obstacles to be taken into account to protect human life and facilitate compliance with the Highway Code were: ignorance of the Highway Code (99.33\%), lack of public lighting, or non-functionality of traffic lights (95.12\%), family concerns $(74.22 \%)$, and the high cost of driving schools $(65.53 \%)$. The weak development of public transport (32.46\%), the high number of «taxi-motorcycles» (35.20\%) as well as the insufficient financial means to buy a new motorcycle (11.29\%) was also mentioned.

\subsection{Psychosocial Interventions}

\subsubsection{Attitudinal Actions to Reduce PRA}

The actions favored at the attitudinal level for the reduction of PRA involving users of motorized two-wheeled vehicles were generalized training on the Highway Code $(91.38 \%)$. Table 3 presents the assessment of the actions to be taken to make the attitudinal aspect more favorable to compliance with the Highway Code.

Table 3. Breakdown of 2 WD users according to the assessment of actions to improve the attitudinal aspect of road safety in the cities of Cotonou and Parakou in 2020 (N=1497).

\begin{tabular}{|c|c|c|c|}
\hline & \multicolumn{3}{|c|}{ Importance (\%) } \\
\hline & Strong & Average & Weak \\
\hline \multicolumn{4}{|l|}{ Attitudinal actions } \\
\hline General training on the highway code & 91,38 & 8,08 & 0,53 \\
\hline Civic education for motorcyclists & 89,25 & 9,42 & 1,34 \\
\hline Raise awareness based on positive messages & 84,24 & 12,56 & 3,21 \\
\hline Raise awareness based on scary messages & 60,92 & 26,05 & 13,03 \\
\hline \multicolumn{4}{|l|}{ Actions facing beliefs } \\
\hline Raise awareness to praise the benefits of respecting the highway code & 96,73 & 3,14 & 0,13 \\
\hline Raise awareness to show the severity of PRA / 2WD & 94,99 & 4,74 & 0,27 \\
\hline Raise awareness to show the limits of motorcycle driving mastery & 91,65 & 7,55 & 0,80 \\
\hline Police repression in the event of non-compliance with the highway code & 87,24 & 9,49 & 3,27 \\
\hline
\end{tabular}

\subsubsection{Actions Against Obstacles and Difficulties on Strict Compliance with the Highway Code}

According to the results of the analysis, more than nine out of ten subjects surveyed prioritized three major actions, namely: Advocacy for the development of infrastructure
$(96,53)$; advocacy for generalized training of all users on the highway code $(94,39)$; and advocacy to make police checks more regular $(87,54)$. Advocating to make technical inspections compulsory in the case of two-wheel drive is among the least recommended actions (41.82\%).

Table 4. Actions in the face of obstacles / difficulties on strict compliance with the Highway Code (N=1497).

\begin{tabular}{|c|c|c|c|}
\hline \multirow{2}{*}{ Variable } & \multicolumn{3}{|c|}{ Importance (\%) } \\
\hline & Strong & Average & Weak \\
\hline Advocacing for infrastructure development & 96,53 & 2,47 & 1,00 \\
\hline Advocacing for the general training of all users on the highway code & 94,39 & 5,28 & 0,33 \\
\hline Advocacing to make police check more regularly & 87,54 & 10,75 & 1,40 \\
\hline Advocacing for compulsory driving license of two-wheel drive & 68,47 & 19,57 & 11,96 \\
\hline Advocacing to make technical visits require as useful & 41,82 & 22,31 & 35,87 \\
\hline Advocacing for the development of public transport & 33,73 & 28,19 & 38,08 \\
\hline Advocacing for the institutionalization of specialized medical visits & 13,63 & 28,39 & 57,98 \\
\hline
\end{tabular}




\subsection{Perception of Sampling Populations on the Relevance of a Combined Approach and the Feasibility of Significantly Reducing PRA / 2 WD}

At the strategic and managerial level, we questioned the sampling populations on the management method to be favored to guarantee the expected efficiency. This involved collecting their perceptions on the relevance with a combined intervention, the choice between a program approach and a project approach, and their perception of the feasibility or not of the significant reduction of PRA among $2 \mathrm{WD}$ in the country. More than $82 \%$ of the subjects surveyed considered relevant the combined interventions, that is to say, those combining awareness and repression. About two-thirds of the representative sample thought that a reduction in PRA is possible, i.e. $66.73 \%$.

\subsection{Final Communication Model Resulting from the Modeling Process}

\subsubsection{Identification of the Determinants for the Significant Reduction of PRA in Urban}

Table 5 shows that the LASSO $(\lambda=0.00398 ; \alpha=1)$ allows at best, to select a restricted subset of explanatory variables associated with the significant reduction or not of the PRA in urban areas.

Table 5. Selecting the best model for a good identification of the determinants.

\begin{tabular}{llllll}
\hline Type of model & Best value of $\boldsymbol{\lambda}$ & Value of $\boldsymbol{\alpha}$ & Accuracy & Sensibility & Rate of true negatives \\
\hline Step AIC & & & - & - & 1 \\
LASSO & 0.00398 & 1 & 0.983 & 0.948 \\
RIDGE & 0.04167 & 0 & 0.978 & 1 & 0.934 \\
& 0.00497 & 0.5 & 0.978 & 1 & 0.934 \\
\hline
\end{tabular}

Table 5. Continued.

\begin{tabular}{llllll}
\hline Type of model & Precision & F-mesure & AUC & Concordance & Observation \\
\hline Step AIC & - & - & - & - & 0.997 \\
LASSO & 0.976 & 0.988 & 0.997 & 0.992 & 0.992 \\
RIDGE & 0.968 & 0.984 & 0.997 & 0.997 & 0.992 \\
ELASTICNET & 0.968 & 0.984 & 0.997 & Same performance problem \\
\hline
\end{tabular}

\subsubsection{Identification of the Best Design of PRA Model with the Input Variable from LASSO Model}

The table 6 provides information on the comparison of the performance criteria of MPNN models as a function of the number of hidden layers for the prediction of the significant reduction or not of PRA in urban areas. It follows that the PMC model with 21 input variables, 5 hidden layers and one output gives the best predictive performance.

Table 6. Identification of the Best Neural Network.

\begin{tabular}{|c|c|c|c|c|c|c|c|}
\hline Model & Accuracy & Sensibility & Rate of True Negative & Precision & F-mesure & AUC & Concordance \\
\hline $\operatorname{PMC}(21,2,1)$ & 0.983 & 0.987 & 0.948 & 0.974 & 0.98 & 0.984 & 0.987 \\
\hline $\operatorname{PMC}(21,5,1)$ & 0.992 & 1 & 0.954 & 0.978 & 0.988 & 0.984 & 0.998 \\
\hline PMC $(21,8,1)$ & 0.978 & 0.993 & 0.95 & 0.974 & 0.984 & 0.982 & 0.991 \\
\hline $\operatorname{PMC}(21,11,1)$ & 0.978 & 0.994 & 0.951 & 0.974 & 0.984 & 0.988 & 0.99 \\
\hline $\operatorname{PMC}(21,15,1)$ & 0.976 & 0.99 & 0.952 & 0.974 & 0.982 & 0.986 & 0.989 \\
\hline $\operatorname{PMC}(21,25,1)$ & 0.975 & 0.99 & 0.954 & 0.974 & 0.982 & 0.987 & 0.991 \\
\hline
\end{tabular}

\subsubsection{Schematic Presentation of the Final Model}

Figure 2 below presents the integrated communication model obtained aimed at reducing PRA involving 2WD in Benin. From this model, it emerges that to significantly reduce PRA among $2 \mathrm{WD}$, it will be necessary to take into account both the individual and psycho-social characteristics of the users, their beliefs and motivation, and the obstacles to compliance with the highway code., with the integration of communication, advocacy and development actions. 


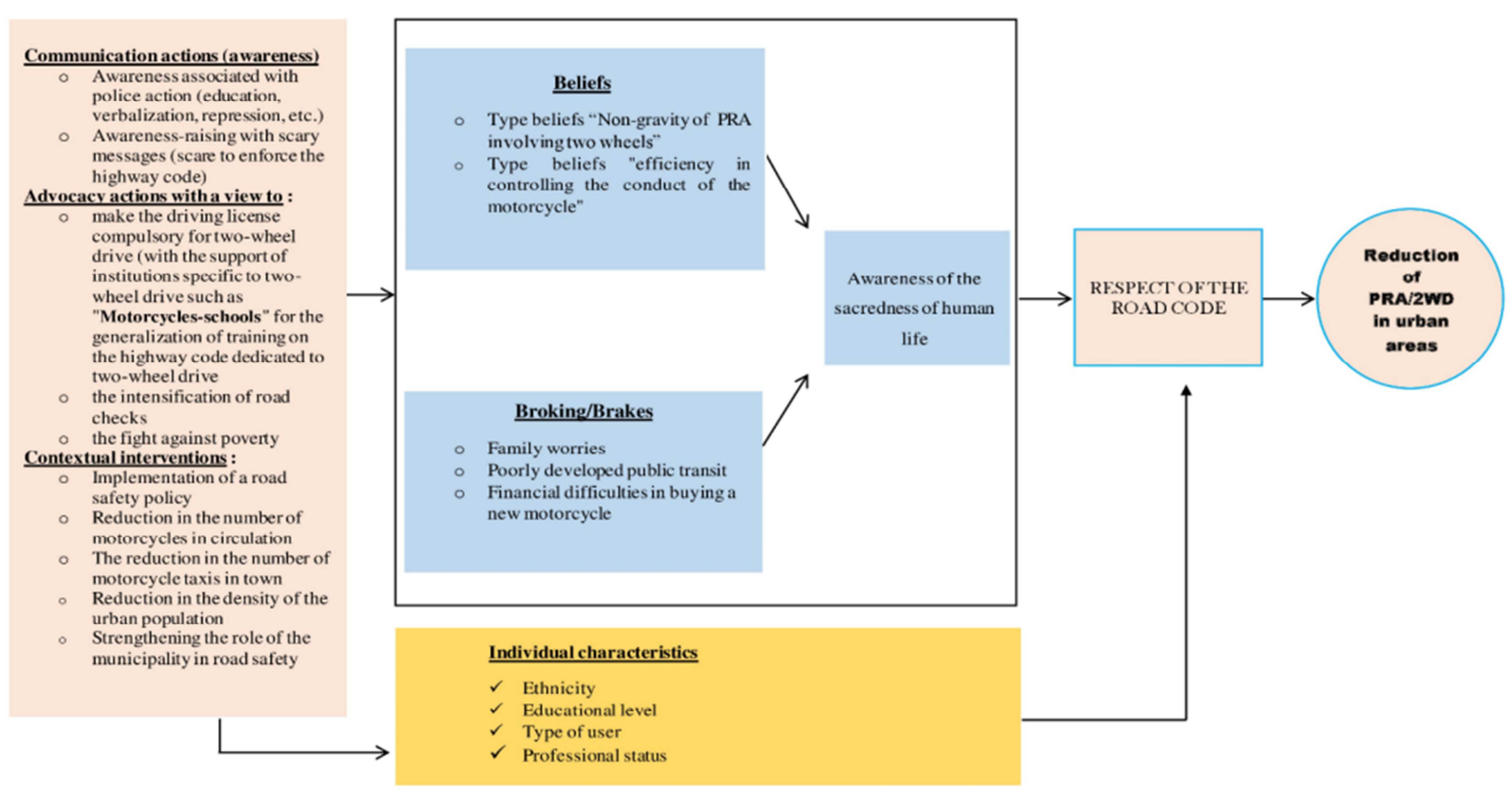

Figure 3. Conceptual framework of the final model for reducing the PRA among $2 W D$ users through integrated communication in Cotonou and Parakou in 2020

\section{Discussion}

The modeling developed during this study led to the identification of a communication model for the reduction of road accidents involving $2 \mathrm{WD}$ in urban areas. The large cities of Cotonou and Parakou in Benin served as the framework for collecting the data used during this modeling We could ask a few questions, once the model sought is known. First, we explored the integrated nature of this model. By definition, in an integrated model there must be a variety of elements that do not fall within the same sector. In this case, the final model obtained is made up of three pillars: communication, advocacy, and development actions. One of the characteristics of this set is the synergy of various elements associating the communication sector with elements that are exogenous to it. This integration was already desired from the conception of the questionnaire at the end of the qualitative phase. If it appears following the statistical analyzes carried out, this reflects the solidity of this principle in the final model. The PMC model that gave the best predictive performance (Accuracy, Sensibility, True Negative Rate, Precision, F-measure, F-measure, and Concordance very close to 1) at the output contained 21 input variables, at 5 layers hidden and at an output gives with the best possible value of the coefficient $\lambda(0,00398)$ and a sensibility close to the value " 1 ". The importance of integration in communication is not first in research. When the authors discuss it, it is expressed in various ways: "integration" [17-19] or "creative work" to mean that respect for the principle of integration is not automatic. The same author came to this conclusion after a "Critical review of communication strategies and evaluation of media campaigns on road safety" in 2013 in Montreal (Canada). Gayrard Pascale (2002) made it a very important aspect at the end of his work [20]: Disabilities and preventable deaths in these terms: "These campaigns must be combined with local training and awareness-raising actions, and support control operations".

For the same author, it is a real behavior change challenge that is therefore matter: "To change behavior, let us understand that training, awareness, communication, continuous monitoring are complementary actions to prevent accidents".

It is for the sake of integrating that several authors have approached the models of behavior change related to health from a psychosocial angle, postulating that, to improve the state of health of the population, it is important to act in both on behavior, motivation, attitudes and beliefs as well as on obstacles to the adoption of the desired behavior. Godwin extracted a so-called "integrator" model [21]. Several resulting health program planning programs have been widely used throughout the world, particularly in the area of road safety. All of the above reinforces the results of the present study which concluded with a final model of communication of the type "integrated persuasive communication" to bring decision-makers and stakeholders at all levels to go beyond periodic thematic campaigns in the field of communication. quest to reduce PRA among 2WD in the specific case of Benin in urban areas. The much soughtafter efficiency in road safety can be achieved if communication (awareness-raising), advocacy, and contextual interventions are used as the main pillars of the action program. We are talking about a program here since nine out of ten representative samples have opted for the program approach as the main mode of managing the 
implementation of this model compared to the "project" approach of recurrent practice in this sector.

The effectiveness of a model can be demonstrated in several ways. In the first place, it is experimentation that is by far the means often used to demonstrate the effectiveness of a model. We are then in the context of an experimental model. If the experimental results are good, the model can be qualified as efficient, if not, it is not. Here it is an experience that proves the effectiveness. But this effect can also be demonstrated outside of experimentation. This is, in essence, the case in the present study. We did not experiment, but we used a methodology that will attest to the likelihood of producing good results if the model is implemented as it should. Indeed, we argue that the final model produced here is effective for five essential reasons. The first reason is related to compliance with the Highway Code, which is known to be effective in terms of preventing road accidents. The second reason is theoretical. The theory used as the basis of our study postulates that the desired effect on the behavior to be adopted is all the higher when the identified factors are correctly applied. However, we have just shown that, if the Highway Code is respected, the reduction of PRA is almost automatic. The third reason is that the final model advocates integration. In a recent study, Agossou et al showed that integration is the guarantee of success of communication actions in the field of road safety in Benin [22]. However, the current model is an integrated model. All these arguments show that the desired efficiency is accessible once the final model is put into practice. The 4th reason is the very essence of the type of communication revealed during this work. This is "persuasive communication" and has been well documented to be effective in enacting behavior change in road safety. Several authors have mentioned it at length in their work $[17,19]$. In the 5 th position, the methodology used on the one hand, and the robustness of the statistical analysis on the other, the exhaustive nature of the factors explored in the analysis, show that the final model does not lack scientific background.

In general, the Highway Code designates a set of laws and regulations relating to the use of public roads by road users (pedestrians, cyclists, users of motorized two-wheelers, motorists, etc.). It contains rules relating to the qualities or skills that a user must have according to the use he makes of the public road (rules related to the user), to the characteristics that a vehicle must have (rules related to the vehicle), the way a user can use the public road, the way users interact with each other, the way the authorities can stand out local rules on certain portions of public roads (road and legislative environment). As PRAs are generally the result of multifactorial processes linked either to the user, to the vehicle or the environment, their occurrence, or their severity, therefore result from non-compliance with the Highway Code. This non-compliance with the Highway Code can take various forms, including speeding, failing to wear a seat belt, crossing a red light, driving while intoxicated, driving under the influence of narcotics, failure to wear a helmet, driving on a prohibited road, unlawful use of a mobile phone or any other communication device while driving a vehicle, etc. Several studies report that these behaviors are associated with an excess risk of PRA. For instance, a meta-analysis of 18 observational studies found that driving under the influence of alcohol increases the risk of stroke in a motor vehicle driver nine-fold. A $1 \%$ increase in the average speed of a vehicle results in a $4 \%$ increase in the risk of a fatal accident [1]. A case-control study in 2016 suggested that not wearing a helmet doubles the risk of trauma after a stroke [23]. Preventing PRA and the consequences associated with it requires a reduction in the prevalence of risk factors, in particular behavioral risk factors for this health problem. This can only be possible by respecting the rules governing the Highway Code that therefore becomes a necessity in the sense that it promotes the adoption of attitudes and behaviors favorable to road safety.

\section{Conclusion}

The results of this study converge entirely on the need to integrate interventions for the prevention of PRA in Benin in a program including both communication actions and those exogenous to the field of communication. This final model results from a modeling process going through three complementary stages. This model presents efficiency advantages with a high probability of significantly reducing road accidents involving motorized two-wheeled vehicles. Also, the principle of integration introduced at the conceptual stage during the preliminary stages of the process before the survey phase emerged as having the highest statistical estimating the performance sought. This research has made it possible to design an integrated model of communication geared towards reducing PRA among 2WD, which constitutes a real public health problem. The implementation of the proposed model will improve the results obtained by using the enabling factors and bypassing the constraints and obstacles that could influence the introduction of the desired changes. Subsequently, this model should be the subject of an experimental study to judge these effects on the various indicators in terms of road safety.

\section{References}

[1] World Health Organization. Global status report on road safety 2018 [Internet]. Geneva: WHO; 2018 [cited 2019 Feb $6]$. website: http://apps.who.int/iris/bitstream/handle/10665/277372/WHONMH-NVI-18.20-fre.pdf?ua=1.

[2] NATIONAL ROAD SAFETY CENTER. Annual report on road accidents in Benin, NRSC; 2015.

[3] World Health Organization. Plan mondial pour la Décennie d'action pour la sécurité routière 2011-2020 [Internet]. 2011 [cité 21 mars 2019]. Disponible sur: https://www.who.int/roadsafety/decade_of_action/plan/plan_fre nch.pdf?ua $=1$. 
[4] World Health Organization. Global status report on road safety 2018 [Internet]. Geneva: WHO; 2016 [cited 2019 Feb $6]$. website: http://apps.who.int/iris/bitstream/handle/10665/277372/WHONMH-NVI-18.20-fre.pdf?ua=1.

[5] World Health Organization. World Health Statistics 2008. Geneva: WHO; 2008 p. 112.

[6] National Institute of Statistics and Economics Analysis (NISEA). The 2002 General Population and Housing Census RGPH3 [Online] 2003. website: https://www.insaebj.org/images/docs/insae-statistiques/enquetesrecensements/RGPH/2.RGPH_3/Rapports-2002/Synthese-desanalyses-rgph3.pdf.

[7] Ministry of Infrastructure and Transport. Yearbook of Statistics 2013-2016 [Internet]. 2017 [cited 2019 Feb 27]. Website: $\quad$ https://transports.bj/wpcontent/uploads/2018/03/Annuaire Statistique TPT 201320 16_VF.pdf.

[8] National Institute of Statistics and Economic Analysis (INSAE). RGPH-4: what to retain from the population in 2013 [Online]. 2015. Website: https://www.insaebj.org/images/docs/insaestatistiques/demographiques/population/Resultats\%20definitif s\%20RGPH4.pdf.

[9] Ogutu J, Shulz-streeck Torben T, Piepho H. Genomic selection using regularized linear regression models: ridge regression, lasso, elastic net and their extension. BMC Proceeding. 2011, 6 (2): 1-6. Website: https://tel.archivesouvertes.fr/file/index/docid/544028/filename/TheseAurelieMo skal.pdf.

[10] Cottrell, Marie and Olteanu, Madalina and Rossi, Fabrice and Rynkiewicz, Joseph and Villa-Vialaneix, Nathalie, 2012. Neural networks for complex data, KI-KünstlicheIntelligenz, 26 (4): 373-380 https://doi.org/10.1007/s13218-012-0207-2.

[11] Graupe Daniel. 2013. Principles of artificial neural networks, Advanced series on circuits and systems World Scientific, (7): 363 pages.

[12] Asogwa, OC and Oladugba, AV. 2015. On The Comparison of Artificial Neural Network (ANN) and Multinomial Logistic Regression (MLR). West African Journal of Industrial and Academic Research, 13 (1): 3-9.
[13] Mollalol, A. and Rivera, M. K. and Vahedi, B. 2020. Artificial Network Modeling of Novel Coronavirus (COVID 19) Incidence Rates across the Continental United States, Int. J. Environ. Res. Public Health, 17 (4204): 1-13 http://doi:10.3390/ijerph17124204.

[14] Hounmenou G. C., Agbangba C. E., Amagbegnon G., Dogbonou B., Kotanmi G. B., GlèlèKakaï R. 2020. A new way of binary variable prediction form selected variables. Artificial Intelligence in Medicine, in press.

[15] Hounmenou, C. G. and Tohoun, R and Gneyou, K. E. and GlèlèKakaï R, 2019. Empirical determination of optimal configuration for characteristics of a multilayer perceptron neural network in nonlinear regression. International Conference on Statistics and Applied Economics (CISEA, ENSEA), Abidjan, Côte d'Ivoire.

[16] R Core Team (2019) R 3.3.6: A Language and Environment for Statistical Computing, $\mathrm{R}$ Foundation for Statistical Computing, Vienna, Austrian. Website: https://www.Rproject.org/.

[17] Ostrom T. The relationship between the affective, behavioral, and cognitive components of attitude. Experimental Social Psychology. 1969; 5 (1): 12-30.

[18] Newcomb T, Turner R, Converse P. Social psychology: The psychology of human interaction. Holt. New York; 1965. 40 p.

[19] Nakatani Y. Developing an oral communication strategy inventory. The modern language journal. 2006; 90 (6): 151-68.

[20] Gayrard Pascale. Road accidents: preventable disabilities and deaths. 2002. website:: https://irepsgp.centredoc.org/index.php?lvl=author_see\&id=354.

[21] Godin G. Change in health behaviors. Treatise on health psychology. 2002. Paris: Dunod, 375-388.

[22] Agossou François, Saizonou Jacques, Mongbo Virginie, Gaffan Nicolas, Hounsa Assomption, Makoutode Patrick et al. Effects of the communication actions implemented to strengthen road safety in Benin. Public health medicine. 2019, 16 (2): 52-77.

[23] Moskal Aurelle. Epidemiology of road trauma in motorized two-wheelers [Thesis]. Lyon: Claude Bernard University; 2009. 